\title{
Comparable frequency of BRCA1, BRCA2 and TP53 germline mutations in a multi-ethnic Asian cohort suggests TP53 screening should be offered together with BRCA1/2 screening to early-onset breast cancer patients
}

Daphne SC Lee', Sook-Yee Yoon ${ }^{1}$, Lai Meng Looi², Peter Kang ${ }^{1}$, In Nee Kang ${ }^{1}$, Kavitta Sivanandan ${ }^{1}$, Hany Ariffin ${ }^{3}$, Meow Keong Thong ${ }^{4}$, Kin Fah Chin ${ }^{5}$, Nur Aishah Mohd Taib ${ }^{3,5}$, Cheng-Har Yip ${ }^{3,5}$ and Soo-Hwang Teo 13,5*

\begin{abstract}
Introduction: Germline TP53 mutations cause an increased risk to early-onset breast cancer in Li-Fraumeni syndrome (LFS) families and the majority of carriers identified through breast cancer cohorts have LFS or LiFraumeni-like (LFL) features. However, in Asia and in many low resource settings, it is challenging to obtain accurate family history and we, therefore, sought to determine whether the presence of early-onset breast cancer is an appropriate selection criteria for germline TP53 testing.

Methods: A total of 100 patients with early-onset breast cancer ( $\leq 35$ years) treated at University Malaya Medical Centre between 2003 and 2009, were analyzed for germline mutations in BRCA1, BRCA2 and TP53 by full DNA sequencing. Of the mutations identified, we examined their likely pathogenicity on the basis of prevalence in a case-control cohort, co-segregation analyses and loss of heterozygosity $(\mathrm{LOH})$ in tumor tissues.
\end{abstract}

Results: We identified 11 BRCA1 (11\%) and 6 BRCA2 (6\%) germline carriers among early-onset breast cancer patients. Of the 83 BRCA-negative patients, we identified four exonic variants and three intronic variants in TP53. Of these, two exonic variants are clinically relevant (E346X and p. G334_R335dup6) and two novel missense mutations (A138V and E285K) are likely to be clinically relevant, on the basis of co-segregation and loss of heterozygosity $(\mathrm{LOH})$. Notably, E285K was found in two unrelated individuals and haplotype analyses suggest a founder effect. Two of the three intronic variants are likely benign based on their prevalence in a control population. Clinically relevant TP53 germline mutations were identified in three of the four patients (75\%) with a family history of at least two LFS-linked cancers (breast, bone or soft tissue sarcoma, brain tumors or adrenocortical cancer); 1 of the 17 patients (6\%) with a family history of breast cancer only, and 1 of the 62 patients $(<2 \%)$ with no family history of breast or LFS-linked cancers.

Conclusions: Our study reports germline BRCA1, BRCA2 and TP53 mutations are found in early-onset breast cancer patients at $11 \%, 6 \%$ and $5 \%$ respectively, suggesting that TP53 mutation screening should be considered for these patients. However, we find that even in low resource Asian settings where family history is poorly reported, germline TP53 mutations are found predominantly among breast cancer patients with a family history of LFS-linked cancers.

\footnotetext{
* Correspondence: soohwang.teo@carif.com.my

${ }^{1}$ Cancer Research Initiatives Foundation, Sime Darby Medical Centre, 1 Jalan

SS12/1A, Subang Jaya, 47500 Selangor, Malaysia

Full list of author information is available at the end of the article
} 


\section{Introduction}

To date, germline mutations in at least 10 genes linked to DNA repair have been shown to be associated with an inherited risk for breast cancer [1]. This includes TP53, a tumor suppressor gene that plays a pivotal role in the cell's response to DNA damage by inducing pathways involved in apoptosis, cell cycle arrest and the DNA repair mechanism in order to maintain the cell's genomic integrity [2].

Although rare, germline mutations in TP53 are associated with a significantly increased risk of female breast cancer, bone or soft tissue sarcomas, brain tumors and adrenocortical carcinomas (ACC) [3-7]. To date, the majority of studies have examined the prevalence of TP53 germline mutations among families identified through the genetics clinics and these studies have shown that the majority of families with germline TP53 mutations fulfill either the original Li-Fraumeni syndrome (LFS) criteria, Li-Fraumeni-like (LFL) criteria or the Chompret criteria and are present with a family history of at least one of the four LFS-linked cancers (breast, bone or soft tissue sarcomas, brain tumors and ACC) $[1,5,8,9]$. More recently, population-based studies have found TP53 germline mutations among women with early-onset breast cancer aged 40 years and below $[10,11]$.

However, the reliance on family history and recruitment through the genetics clinics poses significant challenges in many Asian countries, particularly low and middle income countries such as Malaysia. Clinical genetics services are relatively new and underdeveloped and, moreover, our data and data from Asian Americans have shown that risk assessment models for $B R C A 1$ and $B R C A 2$, which were largely built on families with multiple cancers, underestimate the number of $B R C A$ carriers in Asians compared to Caucasians $[12,13]$. We have previously found that family history is poorly reported in Asian families in Malaysia, in part due to the stigma associated with cancer in Asian families, significant geographical dispersal of families and the lack of robust cancer registries $[12,14]$. There is currently no data in any Asian cohort to determine whether this underestimation of number of carrier families also applies to other genes.

In order to determine the significance of TP53 germline mutations to breast cancer risk in our multi-ethnic cohort, we sought to determine the prevalence of TP53 germline mutations in a hospital-based cohort of Asian breast cancer patients diagnosed before age 35 years. Of the mutations identified, we examined their likely pathogenicity on the basis of prevalence in a case-control cohort, co-segregation analyses and loss of heterozygosity $(\mathrm{LOH})$ studies in tumor tissues.

\section{Materials and methods \\ Cohort selection}

A total of 1,060 breast cancer patients, who were treated at University Malaya Medical Centre, Kuala Lumpur between January 2003 and December 2009, were recruited into the Malaysian Breast Cancer Genetics Study (MyBrCa). All patients gave informed consent and the study was approved by the University Malaya Medical Centre ethics committee.

$B R C A 1$ and BRCA2 sequencing and large chromosomal deletion analysis was conducted in all patients diagnosed with invasive breast cancer aged below 35 years and those with a family history of breast and/or ovarian cancer $[12,15]$. Of the BRCA-negative patients, we screened for germline TP53 mutations in all 83 women who developed invasive breast cancer before 35 years of age, regardless of family history.

\section{Mutation detection}

Genomic DNA isolation and DNA sequencing was conducted as previously described [15]. Full DNA sequencing was carried out in both directions on the entire TP53 coding region and intron-exon boundaries, and annotated using HGVS nomenclature with the GenBank reference sequence NC_000017.9.

\section{Case-control studies}

Genotyping analyses of the seven mutations identified in this study were conducted using the Sequenom MassARRAY platform (San Diego, CA, USA) on 880 women (181 Malays, 530 Chinese, 169 Indians) with invasive breast cancer and on 270 female controls (90 Malays, 90 Chinese, 90 Indians). All mutations identified were confirmed by DNA sequencing.

\section{Haplotyping analyses}

Four TP53 microsatellite markers were used as previously described: p53CA, an intragenic dinucleotide marker; VNTR, a marker with a pentanucleotide repeat in intron 1 [16] and two markers flanking the TP53 gene, D17S786 and D17S796 [17].

\section{Loss of heterozygosity (LOH) analyses}

Where available, 15 to $20 \mu \mathrm{M}$ of formalin fixed paraffinembedded (FFPE) specimens were retrieved for DNA analyses. Each sample had approximately 40 to $80 \%$ tumor cells and genomic DNA was isolated using the QIAamp DNA Mini Kit (Qiagen, Hilden, Germany) according to the manufacturer's protocol. $\mathrm{LOH}$ analyses were conducted by DNA sequencing and genotyped using the Sequenom MassARRAY platform (San Diego, CA, USA). 


\section{Results}

In our ongoing study of breast cancer predisposition genes in a hospital-based cohort of breast cancer patients, we have analyzed $B R C A 1$ and $B R C A 2$ in all patients younger than 35 years diagnosed with invasive breast cancer. Between January 2003 and December 2009, 281 patients were diagnosed with invasive breast cancer before age 35 years at the University Malaya Medical Centre, Kuala Lumpur and 100 patients were recruited into the $\mathrm{MyBrCa}$ study. Of these, $11(11 \%)$ and $6(6 \%)$ were found to have deleterious mutations in BRCA1 and BRCA2 respectively.

We have analyzed germline TP53 mutations in the remaining 83 individuals who tested negative for both BRCA 1 and BRCA2 mutations (Table 1). Of these patients, $4(4.8 \%)$ had a family history of at least one case of the other LFS-linked cancers (bone or soft tissue sarcoma, brain tumors or ACC), 17 (20.5\%) had a family history of breast cancer only, and the remaining 62 had no family history of any of the LFS-linked cancers. Mutation analyses have revealed four unique exonic germline mutations; of which one (E285K) was found in two unrelated individuals, and three unique intronic germline mutations; of which one $(\mathrm{c} .74+14 \mathrm{~T}>\mathrm{C})$ was found in two unrelated individuals (Table 2).

Notably of the five exonic TP53 mutation carriers, three had a family history of LFS-linked cancers, one had two cases of early-onset breast cancer in the family and one had no family history of cancer.

\section{Mutation c.1036 G > T (p. E346X)}

This mutation was found in a Malay individual, BRC 901, with no reported family history of any cancer (Figure 1a). She was diagnosed with breast cancer at age 25 , with recurrence in the same breast at age 26. At age 29, she developed Stage 4 contralateral breast cancer with

Table 1 Characteristics of families recruited into the TP53 study $(n=83)$

\begin{tabular}{lll}
\hline Characteristics & No & (\%) \\
\hline Ethnicity & 29 & 35 \\
$\quad$ Malay & 44 & 53 \\
$\quad$ Chinese & 10 & 12 \\
$\quad$ Indian & & \\
Family history ( $\mathbf{1}^{\circ}$ and $\mathbf{2}^{\circ}$ relatives) & 13 & 16 \\
1 case of breast cancer & 3 & 4 \\
2 cases of breast cancer & 1 & 1 \\
$\geq 3$ cases of breast cancer & 62 & 75 \\
No family history of breast and/or ovarian cancer & 4 & 5 \\
$\geq 1$ case of LFS-linked cancers & 45
\end{tabular}

Table 1 shows the characteristics of 83 BRCA-negative early-onset breast cancer patients analyzed for germline TP53 mutations according to their ethnicity, personal and/or family history of breast cancer in first- and seconddegree relatives and the presence of LFS-linked cancers (breast cancer, bone and soft tissue sarcoma, brain tumors, adrenocortical carcinoma (ACC)) in the families. metastasis to the bones, liver and lungs. This mutation, E346X, was found to be located within the tetramerization domain of TP53 and has previously been reported as a somatic mutation occurring in one tumor only (IARC TP53 database) [18].

\section{Mutation c.1001_1006dup6 (p. G334_R335dup)}

This mutation was found in a Malay individual, BRC 564, whose family showed classic LFS features (Figure 1b). She presented with breast cancer at age 26 and contralateral breast cancer at age 27 , and has one child diagnosed with embryonal rhabdomyosarcoma (ERMS) at eight months and another child with ACC at six months. The patient's mother was diagnosed with breast cancer at age 38 and her younger sister had osteosarcoma at age 26. Upon further analysis, it was found that this family was previously tested in the same hospital for TP53 mutations due to the presence of the childhood cancers. Further analyses have revealed two unaffected children and an unaffected brother as TP53 carriers, in addition to her two affected children and her younger sister with osteosarcoma [19].

This mutation, which is located within the TP53 tetramerization domain, involves a duplication of a $6 \mathrm{bp}$ GGCGTG sequence, which results in an in-frame insertion of two amino acids (Arg and Gly), and is predicted to be likely deleterious.

\section{Mutation c.413 C > T (p. A138V)}

This mutation was found in a Chinese individual, BRC 349, with LFL features (Figure 1c). The proband was diagnosed with breast cancer at age 32, with two sisters (BRC 349A and BRC 349B) affected by breast cancer at 33 and 34 years of age. Notably, one of her sisters, BRC 349A, was subsequently diagnosed with uterine leiomyosarcoma and stomach adenocarcinoma at 43 and 46 years of age, respectively, and was shown to have the same germline TP53 mutation. Her older brother was diagnosed with colorectal cancer at age 33 years, a younger brother was described by the family as having a tumor in the 'gluteal region', her father was affected with liver cancer at an unknown age and a niece was affected with a brain tumor at age 10 .

The A138V mutation was found to be located within the DNA binding domain of TP53. This mutation has previously been reported as a somatic mutation in 51 tumors and, by in silico analysis with Align-GVGD, is predicted to be likely deleterious (IARC TP53 database) [18]. Notably, analysis of the DNA from FFPE breast cancer samples from BRC349 showed loss of the wild type TP53 allele (Figure 2a).

\section{Mutation TP53 c.853 G > A (p. E285K)}

This mutation was found in two unrelated Chinese individuals (Figure 1d, e). The first patient, BRC832, was 
Table 2 Germline TP53 sequence variants identified

\begin{tabular}{|c|c|c|c|c|c|c|c|c|}
\hline No & Exon & $\begin{array}{l}\text { Nucleotide } \\
\text { change }\end{array}$ & $\begin{array}{l}\text { Amino acid } \\
\text { change }\end{array}$ & $\begin{array}{c}\text { Mutation } \\
\text { classification }\end{array}$ & $\begin{array}{l}\text { Previously } \\
\text { reported? }\end{array}$ & $\begin{array}{l}\text { No. of } \\
\text { cases } \\
(n=83)\end{array}$ & Pathogenicity & Ethnicity \\
\hline 1 & 10 & c. $1036 \mathrm{G}>\mathrm{T}$ & p. E346X & Nonsense & Yes $^{1}$ & 1 & Deleterious & Malay \\
\hline 2 & 10 & c. 1001_1006dup6 & p. G334_R335dup & Duplication & Yes $^{2}$ & 1 & $\begin{array}{c}\text { Likely } \\
\text { deleterious }\end{array}$ & Malay \\
\hline 3 & 5 & c. $413 C>T$ & p. A138V & Missense & Yes $^{1}$ & 1 & $\begin{array}{c}\text { Likely } \\
\text { deleterious }\end{array}$ & Chinese \\
\hline 4 & 8 & c. $853 \mathrm{G}>\mathrm{A}$ & p. E285K & Missense & Yes $^{1}$ & 2 & $\begin{array}{c}\text { Likely } \\
\text { deleterious }\end{array}$ & $\overline{\text { Chinese }}$ \\
\hline 5 & $\begin{array}{c}\text { Intron } \\
2\end{array}$ & c. $74+14 \mathrm{~T}>\mathrm{C}$ & - & IVS & Novel & 2 & Likely benign & Chinese \\
\hline 6 & $\begin{array}{c}\text { Intron } \\
3\end{array}$ & c. $97-28 \mathrm{~T}>\mathrm{A}$ & - & IVS & Novel & 1 & Unknown & Chinese \\
\hline 7 & $\begin{array}{c}\text { Intron } \\
6\end{array}$ & c. $672+18 G>C$ & - & IVS & Yes $^{1}$ & 1 & Likely benign & Malay \\
\hline
\end{tabular}

Mutation classification was made based on known databases or published studies.

${ }^{1}$ Reported in IARC TP53 database [18]. ${ }^{2}$ Ariffin et al., 2008 [19]. IVS, intervening sequence

first diagnosed with breast cancer at 31 years, with a recurrence at 33 years. Her mother was diagnosed with breast cancer at age 30 and her brother with a brain tumor at age 20 years.

The second patient, BRC873, developed breast cancer at age 29 and contralateral breast cancer at age 31 . The proband's younger sister, BRC 873A, developed bilateral breast cancer at the ages of 27 and 32, and was shown to have the same germline TP53 mutation. Other family history included her paternal grandmother being affected with breast cancer at 33 years of age and her father having bone cancer at 52 years.

The E285K mutation is located within the DNA binding domain of TP53. This mutation has previously been reported as a somatic mutation in 169 tumors and by in silico analysis with Align-GVGD, is predicted to likely be deleterious (IARC TP53 database) [18]. Haplotype analysis showed that these two families shared the same haplotype across the four microsatellite markers tested (data not shown). Analysis of the DNA from FFPE breast cancer samples from BRC873 showed that there was no loss of the wild type TP53 allele (Figure 2b)

\section{Intronic sequence variants}

We have identified three intervening sequence mutations: c.74+14 $\mathrm{T}>\mathrm{C}$ in two unrelated individuals, and c.97-28 $\mathrm{T}>\mathrm{A}$ and c. $672+18 \mathrm{G}>\mathrm{C}$ in one individual each. The mutation c. $672+18 \mathrm{G}>\mathrm{C}$ was reported as a somatic mutation occurring in three tumors (IARC TP53 database) [18] whereas the remaining two mutations have not previously been reported.

\section{Case-control studies}

None of the four exonic mutations identified in this study or the intervening sequence variant c.97-28 T > A, were found in any of the 880 unselected invasive breast cancer cases and 270 controls tested. Notably, c.74+14 T > C was found in $12 / 880(1.4 \%)$ and $2 / 270(0.74 \%)$ controls, and c. $672+18 \mathrm{G}>\mathrm{C}$ was found in $14 / 880(1.6 \%)$ breast cancer cases and 2/270 $(0.74 \%)$ controls; suggesting that both variants are likely to be benign polymorphisms.

\section{Histopathological analysis}

Breast cancers arising in germline TP53 mutation carriers were previously reported to be more likely to have amplification of HER2 as compared to non-TP53 carriers [20,21].

Of the seven breast cancer patients (five index and two family members) with germline exonic mutations in TP53 available for review, six have strong amplification of the HER-2 receptor (Table 3).

\section{Discussion}

Our study has shown that 5/83 (6\%) of BRCA-negative Asian breast cancer patients diagnosed before age 35 years have germline exonic mutations in TP53 and that the average age of onset of breast cancer was 31 years. This is consistent with reports in other studies, where 0.8 to $5 \%$ frequency was reported among breast cancer patients diagnosed $\leq 40$ years: in an clinic-based cohort of patients $\leq 40$ years, $1 / 126(0.8 \%)$ had a TP53 missense mutation [22]; in a Singaporean clinic-based cohort of breast cancer patients $\leq 35$ years, $1 / 30(3.3 \%)$ patients had a deleterious TP53 mutation [23]: in an Australian population-based cohort of two subgroups of early-onset breast cancer patients ( $\leq 30$ years and 31 to 39 years), 5/94 (5.3\%) had germline TP53 mutations [10].

Notably, in our study, three of the four families with LFS-linked cancers had TP53 germline mutations. Other genetics clinic-based testing showed that classical LFS criteria, LFL criteria or the Chompret criteria are useful 

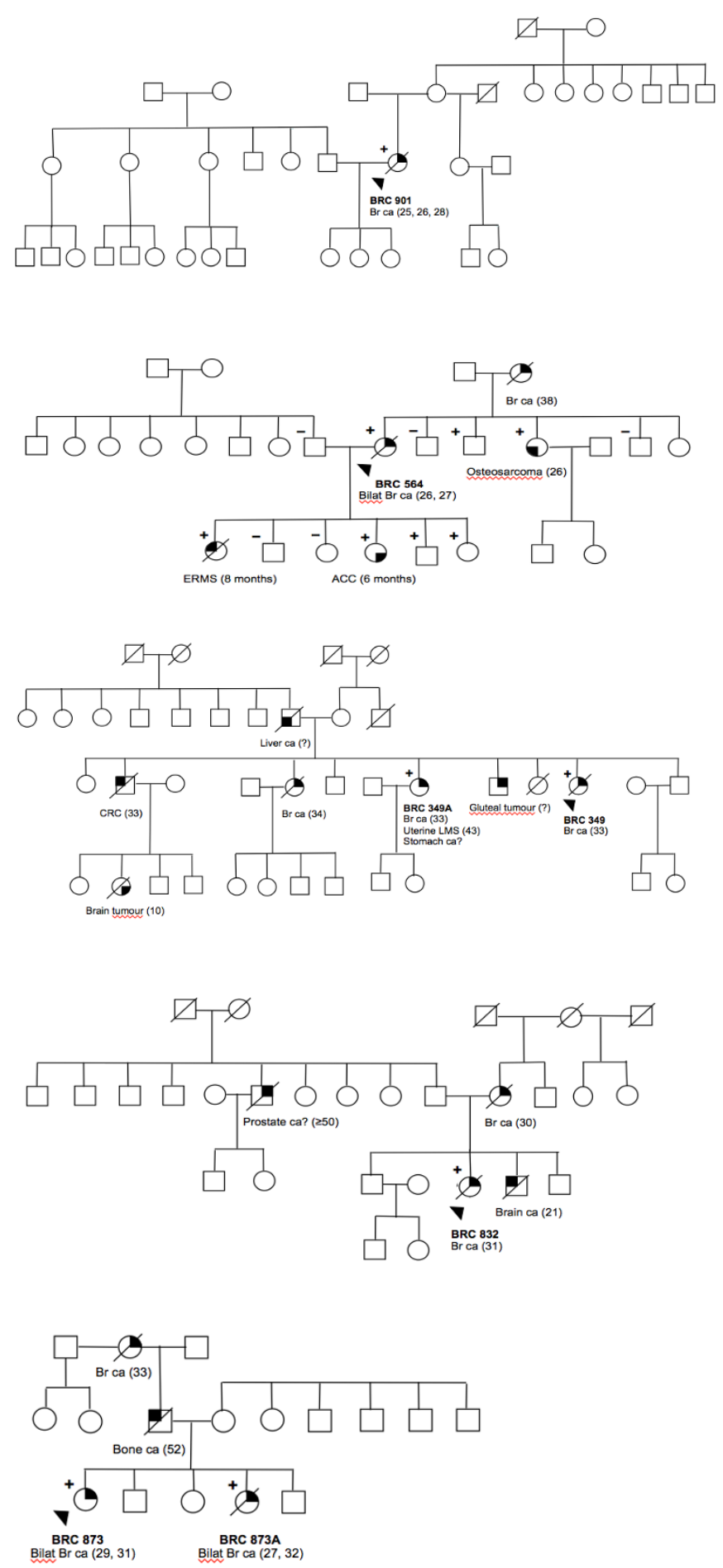

Figure 1 Pedigrees of families with germline exonic mutations in TP53. Pedigrees of the following families: (a) Family BRC 901 with mutation TP53 p. E346X (b) Family BRC 564 with mutation TP53 p. G334_R335dup. (c) Family BRC 349 with mutation TP53 p. A138V (d) Family BRC 832 with mutation TP53 p. E285K (e) Family BRC 873 with mutation TP53 p. E285K. Index patients are indicated with an arrow. Individuals with cancer are indicated with filled symbol quadrants. Deceased individuals are indicated with a slash. Carriers with germline TP53 mutations are indicated with a "+" and non-carriers with a "-". ACC, adrenocortical carcinoma; Br ca, breast cancer; Bilat Br ca, bilateral breast cancer, CRC, colorectal cancer; ERMS, embryonal rhabdomyosarcoma; Uterine LMS, uterine leiomyosarcoma. 


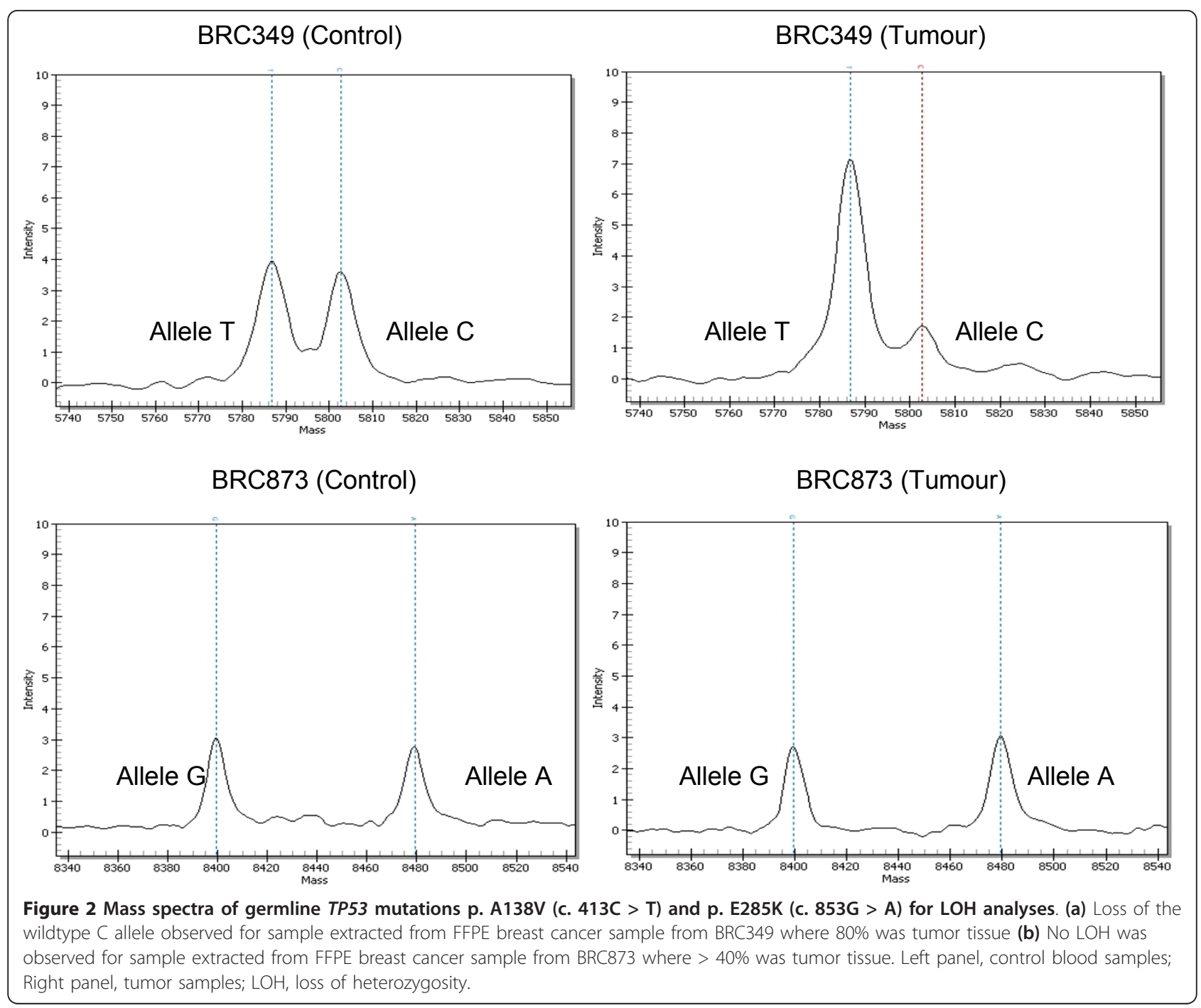

Table 3 Histopathological characteristics of breast cancers in individuals with TP53 germline mutations

\begin{tabular}{|c|c|c|c|c|c|c|c|c|}
\hline Mutation & Patient no. & Age at diagnosis & Diagnosis & Histology & Grade & ER status & PR status & HER-2 status \\
\hline \multirow[t]{3}{*}{ p. E346X } & BRC 901 & 25 & Breast ca, $L$ & IDC with DCIS & $\mathrm{NA}$ & - & + & + \\
\hline & & 26 & Breast ca, L & IDC & 3 & + & + & $3+$ \\
\hline & & 29 & Breast ca, $\mathrm{R}$ & IDC & NA & NA & NA & NA \\
\hline \multirow[t]{2}{*}{ p. G334_R335dup } & BRC 564 & 26 & Breast ca, $\mathrm{R}$ & IDC & NA & NA & NA & NA \\
\hline & & 27 & Breast ca, $\mathrm{L}$ & IDC & 3 & - & + & $3+$ \\
\hline \multirow[t]{2}{*}{ p. A138V } & BRC 349 & 33 & Breast $\mathrm{ca}, \mathrm{R}$ & IDC & 3 & - & - & $3+$ \\
\hline & BRC 349A & 33 & Breast ca, $\mathrm{L}$ & IDC & 2 & - & - & - \\
\hline \multirow[t]{5}{*}{ p. E285K } & BRC 832 & 31 & Breast ca, $\mathrm{R}$ & IDC & 2 & - & - & $3+$ \\
\hline & BRC 873 & 29 & Breast ca, $R$ & IDC with DCIS & 3 & - & - & $3+$ \\
\hline & & 31 & Breast ca, $L$ & NA & $\mathrm{NA}$ & $\mathrm{NA}$ & $\mathrm{NA}$ & NA \\
\hline & BRC 873A & 27 & Breast ca, L & NA & NA & NA & NA & NA \\
\hline & & 31 & Breast $\mathrm{ca}, \mathrm{R}$ & Mucinous & 2 & + & + & $3+$ \\
\hline
\end{tabular}

Breast ca, breast cancer; DCIS, ductal carcinoma in situ; ER, estrogen receptor; IDC, invasive ductal carcinoma; HER-2, human epidermal growth factor receptor 2; $\mathrm{L}$, left; NA, not available; $\mathrm{PR}$, progesterone receptor; $\mathrm{R}$, right 
in selecting families for TP53 testing. In a study of 180 Dutch families, TP53 mutations were found in $22 / 24$ patients who fulfilled the Chrompret criteria and 18/24 patients who fulfilled either classic LFS or LFL criteria [9]. In a clinic-based study of a cohort of 525 individuals, 71/75 TP53 mutation carriers were shown to meet either classic LFS or Chompret criteria [8].

The majority of studies have been from clinical genetics units and recent breast cancer cohort studies suggest that not all germline TP53 mutation carriers meet either classic LFS or LFL criteria. Indeed, in our study, two out of five TP53 mutation carriers did not meet classic LFS or LFL criteria. Similarly, in an Australian study of 94 breast cancer patients, only two out of five carriers met either classic LFS or LFL criteria [10] and in a UKbased study of 100 breast cancer patients, two out of four carriers met these criteria [11].

Our study has identified four exonic mutations (A138V, E285K, E346X and p. G334_R335dup), three of which have not previously been identified as germline mutations. Through co-segregation and $\mathrm{LOH}$ studies, we show that A138V and E285K are likely to be pathogenic. In addition, we show that E285K is recurrent in two unrelated Chinese families. Other recurrent mutations have previously been reported, including the TP53 R337H mutation in southern Brazil [16] and the M133T mutation found in two unrelated African-American families [24], but to the best of our knowledge, this is the first report of a recurrent TP53 mutation in an Asian population.

In addition, our study has also identified three intronic variants (c. $74+14 \mathrm{~T}>\mathrm{C}$, c. $97-28 \mathrm{~T}>\mathrm{A}$ and c. $672+18$ $\mathrm{G}>\mathrm{C}$ ), of which c. $74+14 \mathrm{~T}>\mathrm{C}$ and c. $672+18 \mathrm{G}>\mathrm{C}$ are benign as we show that they are also found in noncancer control individuals.

Notably, in our cohort of early-onset breast cancer patients, $11 \%, 6 \%$ and $5 \%$ had germline mutations in BRCA1, BRCA2 and TP53 respectively. Given the comparable frequency of BRCA1, BRCA2 and TP53 mutations among patients diagnosed at $\leq 35$ years and the high penetrance of TP53 mutations, we suggest that all patients who develop breast cancer at $\leq 35$ years of age should be offered genetic counseling and a family history of LFS-linked cancers should be carefully obtained. Our findings are consistent with the recommendation by the National Comprehensive Cancer Network $(\mathrm{NCNN})$ that all breast cancer patients who are diagnosed before the age of 30 and are BRCA-negative should be offered genetic counseling and testing for TP53 [25].

In addition, our data show that HER2 amplification may be a useful marker in identifying TP53 germline carriers, as six of the seven breast tumors (86\%) in TP53 germline mutation carriers had amplification of ERBB2
(HER2). Previous reports found that 20/29 (69\%) and 10/12 (83\%) of breast tumors from germline TP53 carriers had HER2 amplification or over-expression [20,21] and having a HER-amplified tumor increased the odds of having TP53 germline mutation by nearly seven-fold [21]. These data are consistent with the observation that somatic mutations in TP53 are found in the majority of HER2-amplified tumors, but the mechanism of interdependence between TP53 and HER2 require further work $[20,21]$.

\section{Conclusions}

In conclusion, we show that TP53 germline mutations occur at a comparable frequency with $B R C A 1$ and $B R C A 2$ germline mutations among Asian early-onset breast cancer patients, and occur predominantly, but not exclusively, among families which have a family history of LFS-linked cancers.

\section{Abbreviations}

ACC: adrenocortical cancer; BRCA1: breast cancer 1 gene; BRCA2: breast cancer 2 gene; ERMS: embryonal rhabdomyosarcoma; FFPE: formalin fixed paraffin-embedded; HER2: human epidermal growth factor receptor 2; LFL: li-fraumeni-like; LFS: li-fraumeni syndrome; LOH: loss of heterozygosity; MyBrCa: Malaysian Breast Cancer Study; NCNN: National Comprehensive Cancer Network; TP53: tumor protein 53.

\section{Acknowledgements}

We thank the participants and their families for taking part in this study, and Sze Yee Phuah, Amyza Saleh and Sharifah NurAin for assistance with retrieval of clinical and pathology data and helpful discussions.

This study was funded by the Cancer Research Initiatives Foundation (CARIF) and by research grants from the Malaysian Ministry of Science, Technology and Innovation, Ministry of Higher Education and University Malaya [UM.C/ HIR/MOHE/06].

\section{Author details}

${ }^{1}$ Cancer Research Initiatives Foundation, Sime Darby Medical Centre, 1 Jalan SS12/1A, Subang Jaya, 47500 Selangor, Malaysia. ²Department of Pathology, University Malaya Medical Centre, University Malaya, Kuala Lumpur, Malaysia. ${ }^{3}$ University Malaya Cancer Research Institute, University Malaya Medical Centre, University Malaya, Kuala Lumpur, Malaysia. ${ }^{4}$ Department of Paediatrics, University Malaya Medical Centre, University Malaya, Kuala Lumpur, Malaysia. ${ }^{5}$ Department of Surgery, University Malaya Medical Centre, University Malaya, Kuala Lumpur, Malaysia.

\section{Authors' contributions}

YSY, HA, TMK, CKF, NAMT and YCH recruited patients, collected clinical data and YSY, HA, TMK, NAMT and YCH were responsible for genetic counseling of patients. DSCL and LML conducted pathological analyses, including $L O H$ studies. DSCL, PK, KIN and KS were responsible for laboratory analyses, including sequencing, genotyping and haplotype analyses. DSCL and TSH conceived the study and wrote the manuscript. All authors read and approved the final manuscript.

\section{Competing interests}

The authors declare that they have no competing interests.

Received: 24 October 2011 Revised: 14 February 2012

Accepted: 16 April 2012 Published: 16 April 2012

\section{References}

1. Walsh T, Casadei S, Coats KH, Swisher E, Stray SM, Higgins J, Roach KC, Mandell J, Lee MK, Ciernikova S, Foretova L, Soucek P, King MC: Spectrum 
of mutations in BRCA1, BRCA2, CHEK2, and TP53 in families at high risk of breast cancer. JAMA 2006, 295:1379-1388.

2. Brosh R, Rotter $V$ : When mutants gain new powers: news from the mutant p53 field. Nat Rev Cancer 2009, 9:701-713.

3. Malkin D, Li FP, Strong LC, Fraumeni JF Jr, Nelson CE, Kim DH, Kassel J, Gryka MA, Bischoff FZ, Tainsky MA, Friend SH: Germ line p53 mutations in a familial syndrome of breast cancer, sarcomas, and other neoplasms. Science 1990, 250:1233-1238.

4. Hwang SJ, Lozano G, Amos Cl, Strong LC: Germline p53 mutations in a cohort with childhood sarcoma: sex differences in cancer risk. Am J Hum Genet 2003, 72:975-983.

5. Birch JM, Alston RD, McNally RJ, Evans DG, Kelsey AM, Harris M, Eden OB, Varley JM: Relative frequency and morphology of cancers in carriers of germline TP53 mutations. Oncogene 2001, 20:4621-4628.

6. Chompret A, Abel A, Stoppa-Lyonnet D, Brugieres L, Pages S, Feunteun J, Bonaiti-Pellie C: Sensitivity and predictive value of criteria for p53 germline mutation screening. J Med Genet 2001, 38:43-47.

7. Kleihues P, Schauble B, zur Hausen A, Esteve J, Ohgaki H: Tumors associated with p53 germline mutations: a synopsis of 91 families. Am J Pathol 1997, 150:1-13.

8. Gonzalez KD, Noltner KA, Buzin CH, Gu D, Wen-Fong CY, Nguyen VQ, Han JH, Lowstuter K, Longmate J, Sommer SS, Weitzel JN: Beyond Li Fraumeni Syndrome: clinical characteristics of families with p53 germline mutations. J Clin Oncol 2009, 27:1250-1256.

9. Ruijs MW, Verhoef $S$, Rookus MA, Pruntel $R$, van der Hout $A H$ Hogervorst FB, Kluijt I, Sijmons RH, Aalfs CM, Wagner A, Ausems MGEM, Hoogerbrugge N, van Asperen CJ, Gomez Garcia EB, Meijers-Heijboer H, ten Kate LP, Menko FH, van't Veer LJ: TP53 germline mutation testing in 180 families suspected of Li-Fraumeni syndrome: mutation detection rate and relative frequency of cancers in different familial phenotypes. J Med Genet 2010, 47:421-428.

10. Mouchawar J, Korch C, Byers T, Pitts TM, Li E, McCredie MR, Giles GG, Hopper JL, Southey MC: Population-based estimate of the contribution of TP53 mutations to subgroups of early-onset breast cancer: Australian Breast Cancer Family Study. Cancer Res 2010, 70:4795-4800.

11. Lalloo F, Varley J, Moran A, Ellis D, O'Dair L, Pharoah P, Antoniou A, Hartley R, Shenton A, Seal S, Bulman B, Howell A, Evans DGR: BRCA1, BRCA2 and TP53 mutations in very early-onset breast cancer with associated risks to relatives. Eur J Cancer 2006, 42:1143-1150.

12. Thirthagiri E, Lee SY, Kang P, Lee DS, Toh GT, Selamat S, Yoon SY, Taib NA, Thong MK, Yip CH, Teo SH: Evaluation of BRCA1 and BRCA2 mutations and risk-prediction models in a typical Asian country (Malaysia) with a relatively low incidence of breast cancer. Breast Cancer Res 2008, 10:R59.

13. Kurian AW, Gong GD, Chun NM, Mills MA, Staton AD, Kingham KE, Crawford BB, Lee R, Chan S, Donlon SS, Ridge Y, Panabaker K, West DW, Whittemore AS, Ford JM: Performance of BRCA1/2 mutation prediction models in Asian Americans. J Clin Oncol 2008, 26:4752-4758.

14. Yoon SY, Thong MK, Taib NA, Yip CH, Teo SH: Genetic counseling for patients and families with hereditary breast and ovarian cancer in a developing Asian country: an observational descriptive study. Fam Cancer 2011, 10:199-205.

15. Toh GT, Kang P, Lee SS, Lee DS, Lee SY, Selamat S, Mohd Taib NA, Yoon SY, Yip CH, Teo SH: BRCA1 and BRCA2 germline mutations in Malaysian women with early-onset breast cancer without a family history. PloS one 2008, 3:e2024.

16. Pinto $E M$, Billerbeck $A E$, Villares $M C$, Domenice $S$, Mendonca $B B$, Latronico AC: Founder effect for the highly prevalent R337H mutation of tumor suppressor p53 in Brazilian patients with adrenocortical tumors. Ara Bras Endocrinol Metabol 2004, 48:647-650.

17. Murthy SK, DiFrancesco LM, Ogilvie RT, Demetrick DJ: Loss of heterozygosity associated with uniparental disomy in breast carcinoma. Mod Pathol 2002, 15:1241-1250.

18. Petitjean A, Mathe E, Kato S, Ishioka C, Tavtigian SV, Hainaut P, Olivier M: Impact of mutant p53 functional properties on TP53 mutation patterns and tumor phenotype: lessons from recent developments in the IARC TP53 database. Hum Mutat 2007, 28:622-629.

19. Ariffin H, Martel-Planche G, Daud SS, Ibrahim K, Hainaut P: Li-Fraumeni syndrome in a Malaysian kindred. Cancer Genet Cytogenet 2008, 186:49-53.

20. Wilson JR, Bateman AC, Hanson H, An Q, Evans G, Rahman N, Jones JL, Eccles DM: A novel HER2-positive breast cancer phenotype arising from germline TP53 mutations. J Med Genet 2010, 47:771-774.
21. Melhem-Bertrandt A, Bojadzieva J, Ready KJ, Obeid E, Liu DD, GutierrezBarrera AM, Litton JK, Olopade OI, Hortobagyi GN, Strong LC, Arun BK: Early onset HER2-positive breast cancer is associated with germline TP53 mutations. Cancer 2011, 118:908-913.

22. Sidransky D, Tokino T, Helzlsouer K, Zehnbauer B, Rausch G, Shelton B, Prestigiacomo L, Vogelstein B, Davidson N: Inherited p53 gene mutations in breast cancer. Cancer Res 1992, 52:2984-2986.

23. Ang P, Lim IH, Yong RY, Lee AS: A molecular approach for identifying individuals with Li-Fraumeni syndrome who have a limited family history. Clin Genet 2009, 75:294-297.

24. Hung J, Mims B, Lozano G, Strong L, Harvey C, Chen TT, Stastny V, Tomlinson G: TP53 mutation and haplotype analysis of two large African American families. Hum Mutat 1999, 14:216-221.

25. The National Comprehensive Cancer Network (NCNN) Guidelines for Detection, Prevention \& Risk reduction; Genetic/Familial High-Risk Assessment:Breast and Ovarian, Li-Fraumeni Syndrome ver 1.2011. [http://www.nccn.org/professionals/physician_gls/f_guidelines.asp].

doi:10.1186/bcr3172

Cite this article as: Lee et al:: Comparable frequency of $B R C A 1, B R C A 2$ and TP53 germline mutations in a multi-ethnic Asian cohort suggests TP53 screening should be offered together with BRCA1/2 screening to early-onset breast cancer patients. Breast Cancer Research 2012 14:R66.

\section{Submit your next manuscript to BioMed Central and take full advantage of:}

- Convenient online submission

- Thorough peer review

- No space constraints or color figure charges

- Immediate publication on acceptance

- Inclusion in PubMed, CAS, Scopus and Google Scholar

- Research which is freely available for redistribution 